Research Article

\title{
The Time Effect and Micromechanism of the Unconfined Compressive Strength of Cement Modified Slurries
}

\author{
Ping Jiang $\mathbb{D}^{1,2}$ Yewen Chen $\mathbb{D}^{1,},{ }^{1}$ Lin Zhou $\mathbb{D}^{1},{ }^{1}$ Tianhao Mao, ${ }^{1}$ Wei Wang, ${ }^{1}$ Junping Yuan, ${ }^{2}$ \\ and $\mathrm{Na} \operatorname{Li}{ }^{1}$ \\ ${ }^{1}$ School of Civil Engineering, Shaoxing University, Shaoxing 312000, China \\ ${ }^{2}$ Key Laboratory of Ministry of Education for Geomechanics and Embankment Engineering, Hohai University, \\ Nanjing 210098, China
}

Correspondence should be addressed to Na Li; lina@usx.edu.cn

Received 18 January 2021; Revised 11 March 2021; Accepted 3 April 2021; Published 19 April 2021

Academic Editor: Qinglin Guo

Copyright (c) 2021 Ping Jiang et al. This is an open access article distributed under the Creative Commons Attribution License, which permits unrestricted use, distribution, and reproduction in any medium, provided the original work is properly cited.

\begin{abstract}
This study investigated the unconfined compressive strength change law of cement modified slurries (CMS) under different curing ages. We conducted unconfined compressive strength tests using slurry and cement as raw materials. The cement contents were $5 \%, 10 \%, 15 \%, 20 \%$, and $25 \%$. The curing ages were $7,14,28,56,90,120,150$, and $180 \mathrm{~d}$. A time effect model of CMS strength was established based on the measured UCS strength-curing age and the strength-cement content curves. The test results proved that the UCS of the CMS increased significantly with an increase in the curing age, and after 90 days, the UCS gradually increased to a fixed value. The time effect model better characterized the relationship between the UCS of the CMS and the curing age and the cement content, as the predicted value had a high correlation with the measured value. We conducted scanning electron microscopy (SEM), energy dispersive X-ray (EDX), and X-ray diffraction (XRD) tests to analyze the microstructure and chemical composition of the CMS. The microscopic test results demonstrated that the increase of cement content and curing age increased the amount of gelling substances in the CMS and made the overall structure more compact, thereby increasing its macro strength.
\end{abstract}

\section{Introduction}

Slurry is a type of turbid suspension system composed of water, bentonite particles, clay particles, and admixtures. Generally, in slurry preparation, water accounts for $70 \%$ to $80 \%$, and solid particles account for $20 \%$ to $30 \%$, by volume ratio. As an engineering auxiliary construction material, slurries are widely used in bored pile construction, shield tunnel construction, and underground diaphragm wall construction. An unreasonable discharge of construction slurry will cause environmental pollution, water pollution, vegetation destruction, and soil consolidation, thereby destroying the ecological environment. Thus, there is an urgent need for social development to find an economical and environmentally friendly treatment method to deal with the waste slurry.

A large amount of earth rock materials is used in highway engineering construction. This is an effective method of resource utilization through curing and modifying the slurry to meet the requirements of highway engineering. Many studies have been carried out on the methods of slurry curing [1-3]. However, the study of slurry curing with high-moisture content requires further discussion [4].

Cement, as a kind of commonly used soft soil curing material, has been well researched [5-10]. Pu [11] performed unconfined compression tests on silt samples and SEU-2 binder-cured silt samples. The brittleness index was introduced to quantitatively evaluate the softening and hardening effects of curing silt. The test results demonstrated that the addition of cement improved the deformation characteristics of silt. With the increase of cement content, the initial porosity and compression index decreased. The unconfined compressive strength (UCS) increased with increasing curing age and cement content, while the failure strain decreased. There are also some studies on the incorporation 
of waste materials into soft soil, which not only recycled the waste, but also modified the soft soil. Yoobanpot [12] added cement kiln ash and fly ash into soft soil to improve its compressive strength. The strength of the soft soil was significantly improved early on and slowly increased with an increase in the curing age.

Cement can improve the engineering properties of soft soil, and the UCS of cement soil increases with the increase in curing age. So, cement soil is widely used in many engineering fields, just as bored pile construction, shield tunnel construction, and underground diaphragm wall construction [13-21]. Many studies on the mathematical model of strength growth were conducted. Horpibulsuk studied the strength growth law of high-moisture cement soil based on Abrams' method and put forward the prediction of cement soil strength with the water-cement ratio as the basic parameter [22]. Lee proposed that the strength of the cement soil was related to the cement content and water-cement ratio and thus established a mathematical model [23]. Based on Lee's research, Xiao and Liu proposed a generalized hyperbolic fitting mathematical model for the time effect of cement soil $[24,25]$. The above results demonstrated that the UCS of cement soil is related to the cement content and curing age. As slurries and soft soils have similar engineering characteristics, it is feasible to establish a time effect model of cement modified slurries (CMS).

The analysis of micromechanisms has important guidance for macro-mechanical research. At present, the microtests of cement soil mainly use scanning electron microscopy (SEM), energy dispersive X-ray (EDX), and $\mathrm{X}$-ray diffraction (XRD). The SEM analysis of cement stabilized soil conducted by Mousavi [26] demonstrated that cement could improve the strength of soil due to the hydration reaction. During the reaction process, cement filled the smaller pores in the soil and produced gel crystals with the increasing curing age. The space of the large pores gradually decreased. Mola-Abasi [27] incorporated zeolite into the cement sand, and the SEM tests showed that zeolite changed the microstructure of the cement sand. The reaction products of pozzolan filled the porous cement sand, thereby, increasing its strength.

Ghasabkolaei [28] performed SEM image analysis on the cemented soil mixed with and without nanosilicon powder, and the results demonstrated that the cemented soil mixed with nanosilicon power was more uniform and denser than the ordinary cemented soil. Moreover, the UCS of uniformly dense cement soil mixed with nanosilicon powder is high. Homidy [29] studied the microstructure of cement soil. SEM image analysis showed that the schistose structure in the cement soil was caused by the hydration reaction of the cement. XRD diffraction analysis showed that the $\mathrm{C}-\mathrm{S}-\mathrm{H}$ gel formed by the hydration reaction results in the highest proportion of calcium and silicon among all the elements.

The above studies demonstrated that the mechanical properties of slurry can be effectively improved by adding modified materials. Cement is a commonly used modification material due to the advantages of low cost and good modification effects. Using cement is feasible for modifications of slurries. Through studying the changes of the mechanical properties of CMS over extended curing ages, relevant mathematical models were established to effectively predict the key indexes. Through the microtests of CMS, the strength variation mechanism can be explained from the micromechanism aspect, which can provide a reference for the engineering applications of modified slurries.

\section{Test Preparation}

2.1. Experimental Materials and Program. The raw materials used in this study are slurry and cement, and the moisture content of the slurry is $100 \%$. The slurry used throughout the experimental test was collected from a construction site in Shaoxing city, China, as shown in Figure 1. The physical and mechanical properties of the slurry are presented in Table 1. SEM, EDX, and XRD tests were performed on the dried slurry, and the microstructure, elemental composition, and compound composition were obtained as shown in Figures 2-4, respectively.

As demonstrated in Figures 2-4, the slurry was mainly composed of schistose particles, whose main element components were $\mathrm{Si}, \mathrm{O}, \mathrm{Al}, \mathrm{Mg}$, and $\mathrm{Ca}$, whose main compounds were $\mathrm{SiO}_{2}, \mathrm{Al}_{2} \mathrm{O}_{3}$, and $\mathrm{CaCO}_{3}$.

The cement used in this test belongs to class PO32.5, ordinary Portland cement, produced by Shangyu Hailuo Cement Co., Ltd. The cement content and the curing age of CMS are presented in Table 2.

2.2. Sample Making and Testing. According to the highway geotechnical test regulations [30], the amount of slurry was calculated based on the proposed test scheme, then placed in a mixer, and stirred for three minutes to ensure uniformity. The cement was added, according to Table 2, as a percentage of the dried slurry weight, and then stirred for 3 to 5 minutes. The mixed CMS was charged into the test mold three times and shaken 50 times each charge. The size of the test mold was a cylinder with a diameter of $39.1 \mathrm{~mm}$ and a height of $80 \mathrm{~mm}$. Then, the test mold was sealed with cling film and left vertically in position for 2 hours. After the entire sample was solidified and stabilized, both ends of the sample were wrapped with filter paper and placed into a water tank for curing at $20^{\circ} \mathrm{C}$. The curing ages were $7 \mathrm{~d}, 14 \mathrm{~d}, 28 \mathrm{~d}, 56 \mathrm{~d}$, $90 \mathrm{~d}, 120 \mathrm{~d}, 150 \mathrm{~d}$, and $180 \mathrm{~d}$. The cured samples were demoulded, and then the UCS tests were conducted. The demoulded samples are shown in Figure 5. In this study, the UCS tests were performed using a fully automatic multifunctional unconfined compressive strength tester produced by Nanjing TKA Technology Co., Ltd., which can realize the automation of the whole process of test operation through computer control.

\section{UCS Test Results and Analysis}

3.1. UCS Test Results. The stress-strain data curves of CMS measured by UCS tests with different cement contents and different curing ages are shown in Figure 6, where 6(a)-6(h) represent the stress-strain curves with different cement contents at curing ages of $7 \mathrm{~d}, 14 \mathrm{~d}, 28 \mathrm{~d}, 56 \mathrm{~d}, 90 \mathrm{~d}, 120 \mathrm{~d}$, $150 \mathrm{~d}$, and $180 \mathrm{~d}$, respectively. 


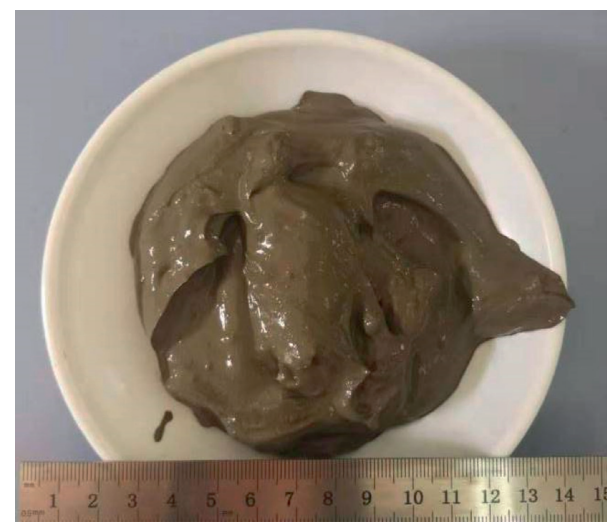

FIgURE 1: The testing slurry.

TABLE 1: The physical and mechanical properties of the building slurry.

\begin{tabular}{lccccc}
\hline Index name & Specific gravity & Liquid limit/(\%) & Plastic limit/(\%) & Plasticity index/(\%) & Moisture content/(\%) \\
\hline Index value & 2.65 & 43.5 & 23.1 & 20.4 & 100 \\
\hline
\end{tabular}

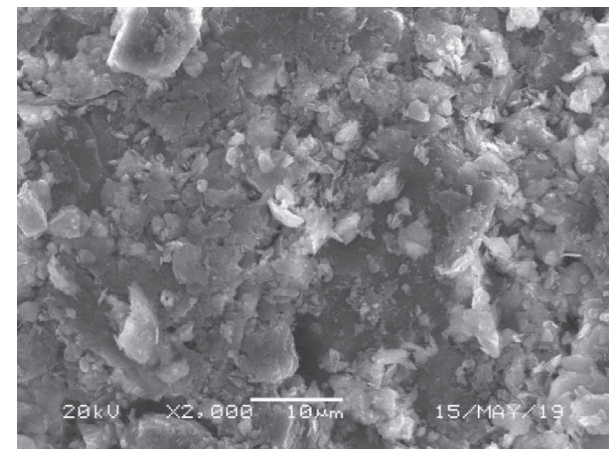

FIGURE 2: The scanning electron microscopy (SEM) test results of the slurry.

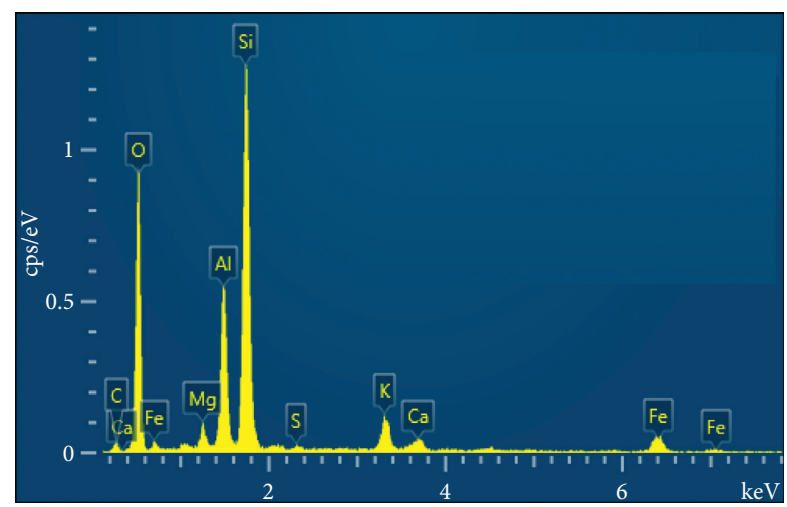

General spectrum

FIgure 3: The energy dispersive X-ray (EDX) test results of the slurry.

In Figure 6, there are obvious peaks in the unconfined compressive stress-strain curves of CMS with different cement contents and at different curing ages, which has a softening curve characteristic; that is, when the stress does

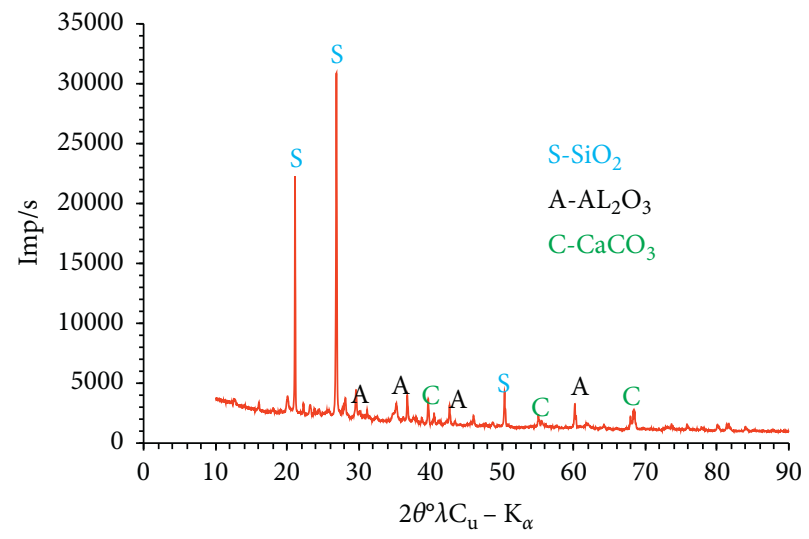

Figure 4: The X-ray diffraction (XRD) test results of the slurry.

TABLE 2: The unconfined compressive strength (UCS) test scheme.

\begin{tabular}{lc}
\hline Cement content/(\%) & Curing age/(d) \\
\hline $5,10,15,20,25$ & $7,14,28,56,90,120,150,180$ \\
\hline
\end{tabular}

not reach the peak, the stress increases sharply with the increase of the strain. When the stress reaches its peak value, the stress slowly decreases with increasing strain and finally tends towards a stable value.

3.2. UCS Test Data Analysis. The peak stress of the unconfined compressive stress-strain curve is taken as the UCS of the CMS. According to the stress-strain curve in Figure 6, the UCS of the CMS with different cement contents at different curing ages can be obtained, as presented in Table 3 .

According to Table 3, the comparison of the UCS of the CMS at different curing ages with different cement contents was obtained, as shown in Figure 7.

Figure 7 shows that the UCS of the CMS at each curing age increased with the increase of cement content. In 


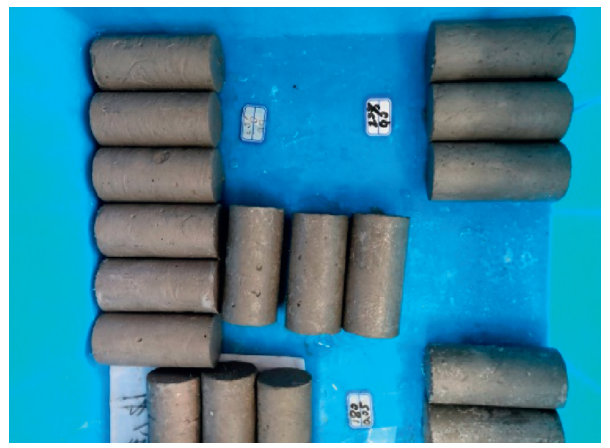

FIGURE 5: The demoulded cement modified slurry (CMS) sample.
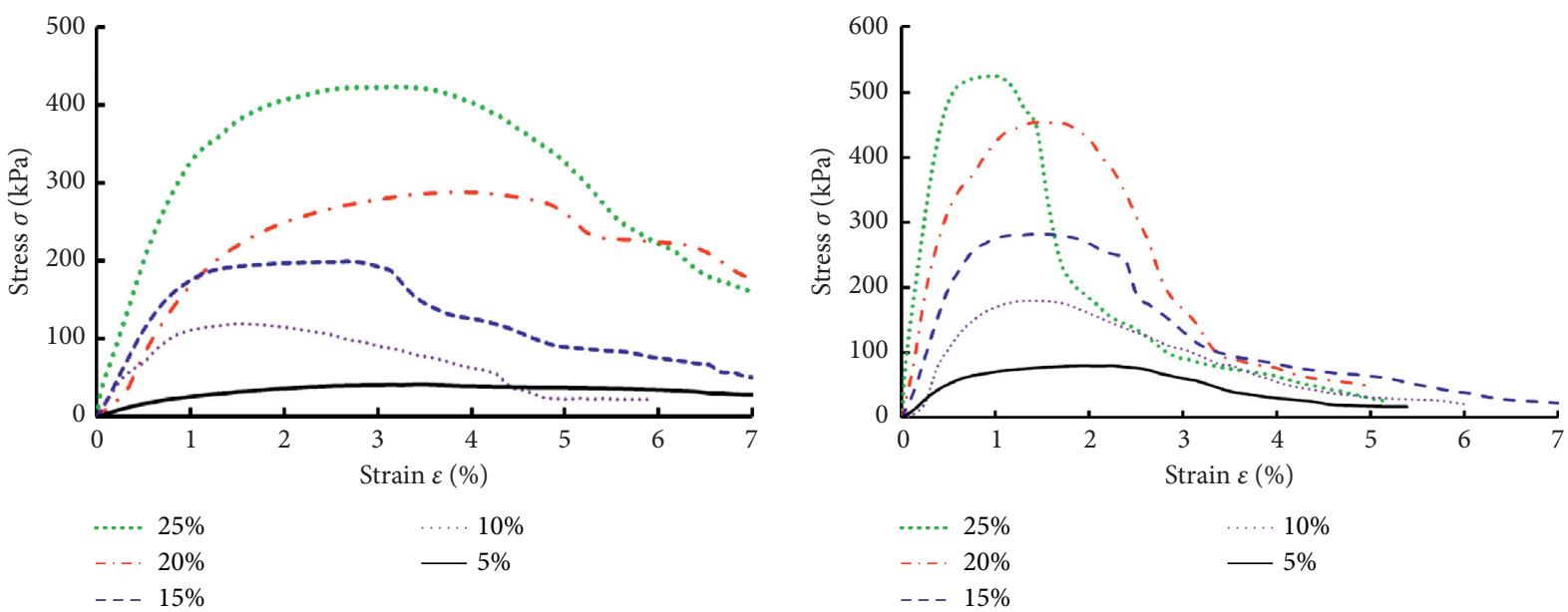

(a)

(b)
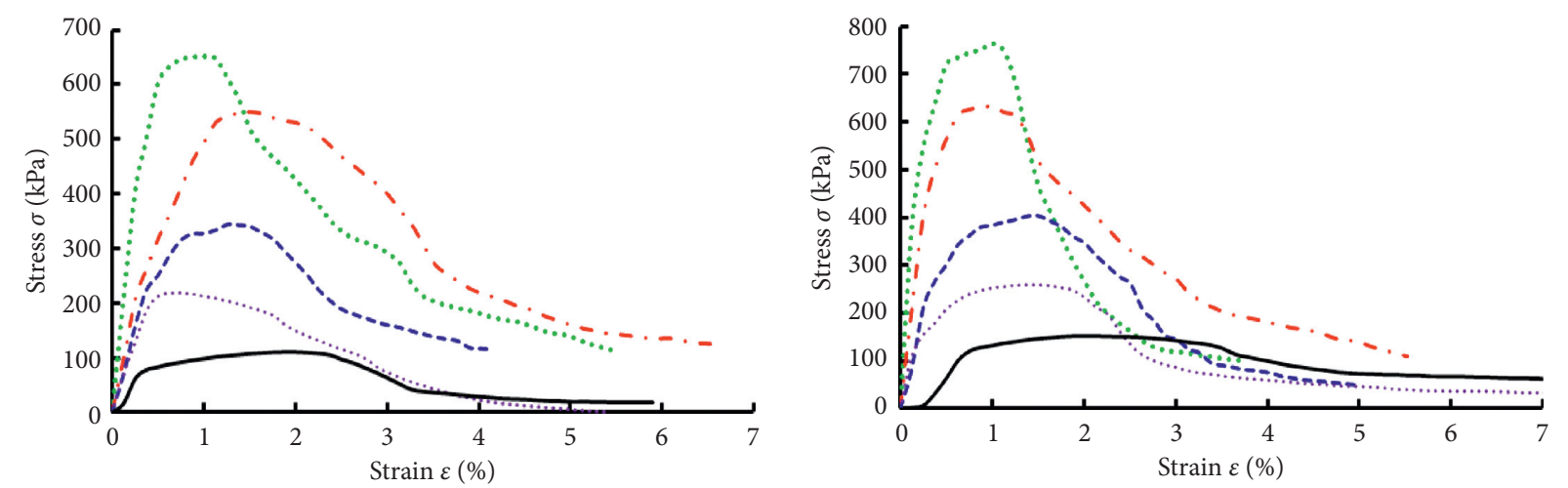

.... $25 \%$
-. $20 \%$
- - $15 \%$

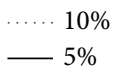

$\begin{array}{ll}\ldots . . . & 25 \% \\ -.-. & 20 \% \\ - & 15 \%\end{array}$

….. $10 \%$

- - $15 \%$

(c)

(d)

Figure 6: Continued. 


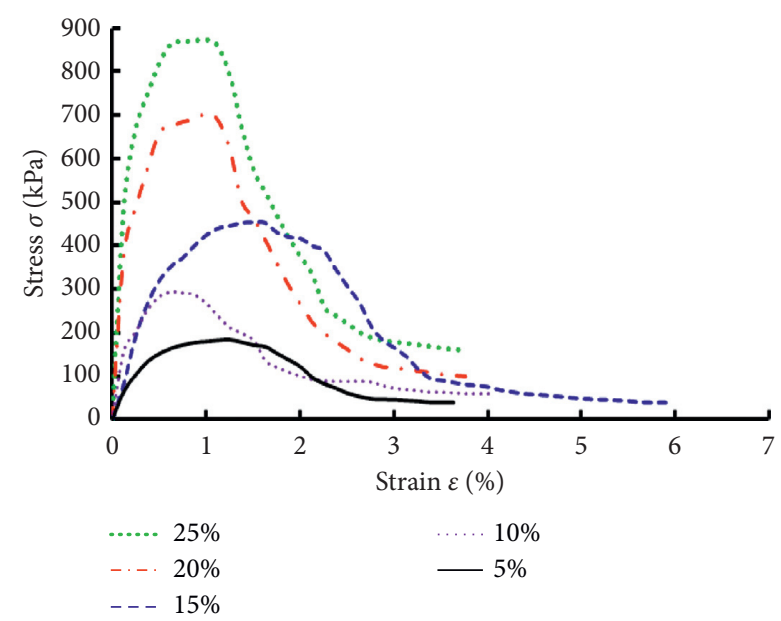

(e)

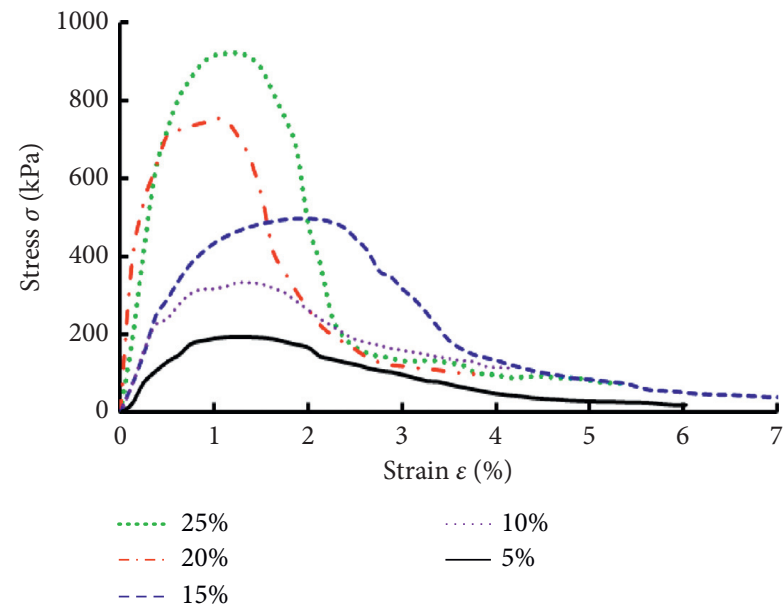

(g)

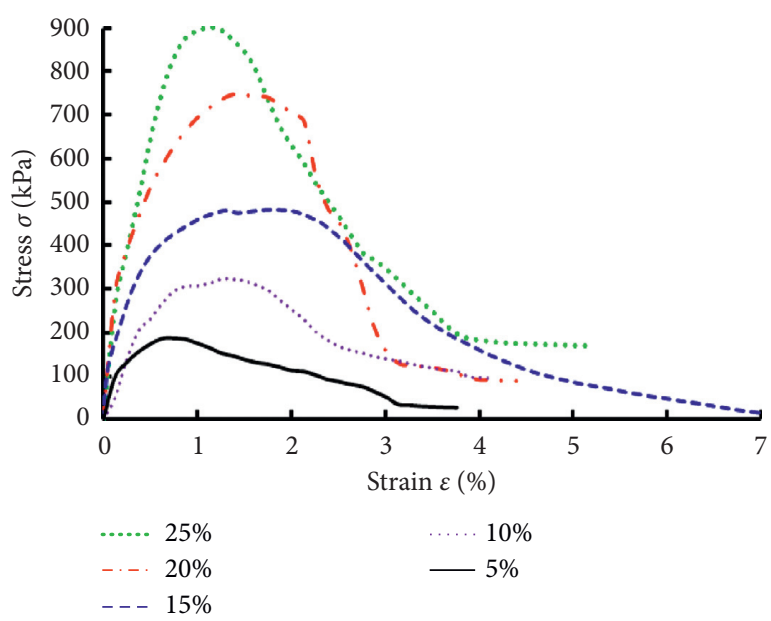

(f)

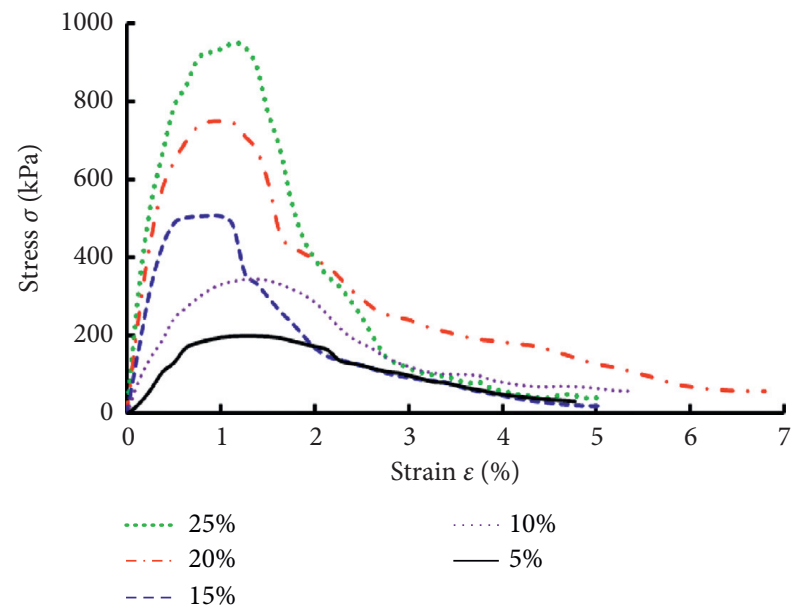

(h)

FIgURE 6: Axial stress and axial strain curves of CMS. (a) $7 \mathrm{~d}$ axial stress and axial strain curves. (b) $14 \mathrm{~d}$ axial stress and axial strain curves. (c) $28 \mathrm{~d}$ axial stress and axial strain curves. (d) $56 \mathrm{~d}$ axial stress and axial strain curves. (e) $90 \mathrm{~d}$ axial stress and axial strain curves. (f) $120 \mathrm{~d}$ axial stress and axial strain curves. (g) $150 \mathrm{~d}$ axial stress and axial strain curves. (h) $180 \mathrm{~d}$ axial stress and axial strain curves.

TABLE 3: The UCS of the CMS/kPa.

\begin{tabular}{lccccc}
\hline Curing age/(d) & \multicolumn{3}{c}{ Cement content/(\%) } & 20 & 25 \\
\hline 7 & 5 & 10 & 15 & 298 & 423 \\
14 & 43 & 122 & 283 & 448 & 518 \\
28 & 81 & 179 & 339 & 553 & 625 \\
56 & 113 & 221 & 404 & 701 & 755 \\
90 & 151 & 248 & 448 & 743 \\
120 & 184 & 288 & 478 & 752 \\
150 & 194 & 322 & 489 & 796 \\
180 & 195 & 331 & 502 & 918 \\
\hline
\end{tabular}

addition, the growth rate of the UCS with a cement content from $20 \%$ to $25 \%$ clearly decreased. We concluded that the $20 \%$ cement content was the optimal content.
In order to further explore the effect of the cement content on the UCS of the CMS, the strength growth multiples of the CMS with different cement contents can be 


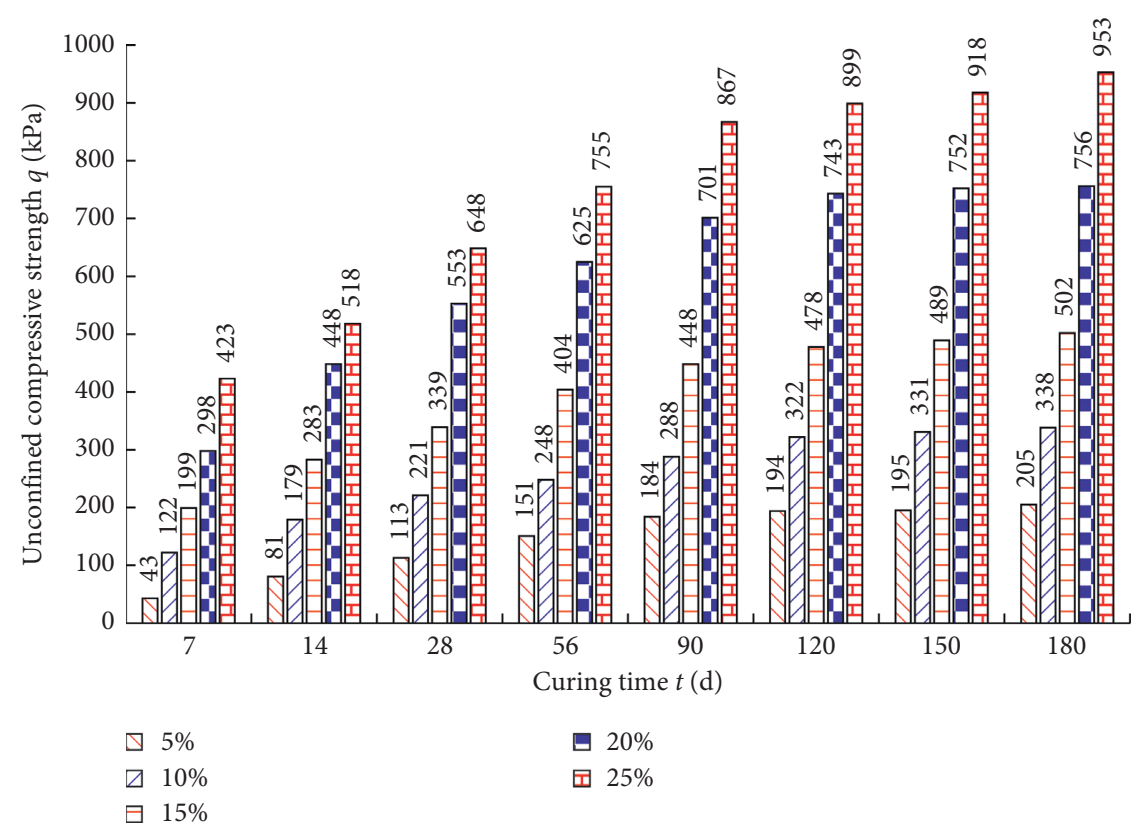

Figure 7: The UCS of the CMS with different cement contents at different curing ages.

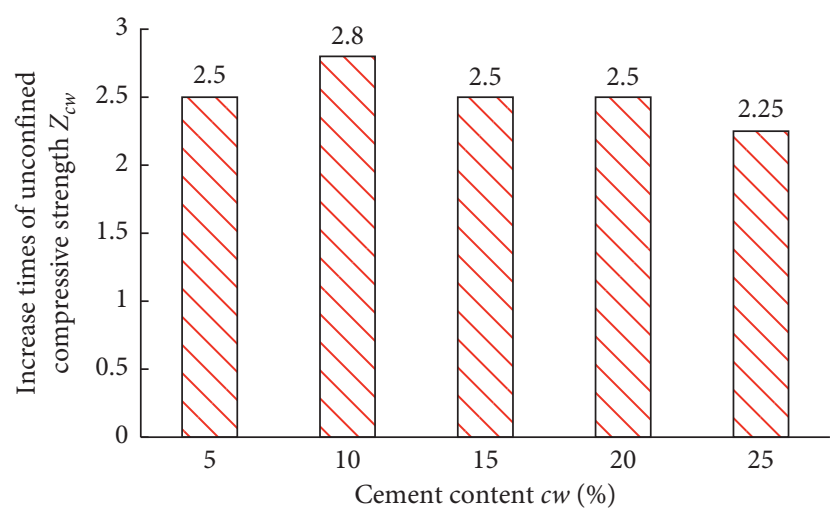

FIgURe 8: Multiple changes in the strength of CMS with different cement contents during the curing process.

calculated according to formula (1), and the calculated results are shown in Figure 8.

$$
Z_{c w}=\frac{q_{180 d}}{q_{7 d}}
$$

where $Z_{c w}$ represents the multiple, and $q_{180 d}$ and $q_{7 d}$ represents the UCS of the CMS at curing ages of $180 \mathrm{~d}$ and $7 \mathrm{~d}$, respectively.

In Figure 8, the UCS of the CMS with each cement content increased by 2.5 times with the increase in curing age.

According to Table 3, the comparison of the UCS of the CMS with different cement contents and different curing ages is shown in Figure 9.

In Figure 9, with the same cement content, the UCS of the CMS increased significantly with the curing age from $7 \mathrm{~d}$ to $90 \mathrm{~d}$. During the curing from $120 \mathrm{~d}$ to $180 \mathrm{~d}$, the UCS of the CMS did not increase significantly.
In order to further explore the effect of the curing age on the UCS of the CMS, the strength multiples of the CMS at different curing ages were calculated according to formula (2), and the calculated results are shown in Figure 10.

$$
Z_{d}=\frac{\sigma_{25 \%}}{\sigma_{5 \%}}
$$

where $Z_{d}$ represents the multiple, $\sigma_{25 \%}$ represents the peak strength of the CMS when the cement content is $25 \%$, and $\sigma_{5 \%}$ represents the peak strength of the CMS when the cement content is $5 \%$.

As can be seen from Figure 10, with the increase in the curing age, the strength increased multiple times, gradually decreased, and finally reached a stable value.

3.3. Time Effect Model. In order to comprehensively analyze the improvement effect of the cement content and the curing 


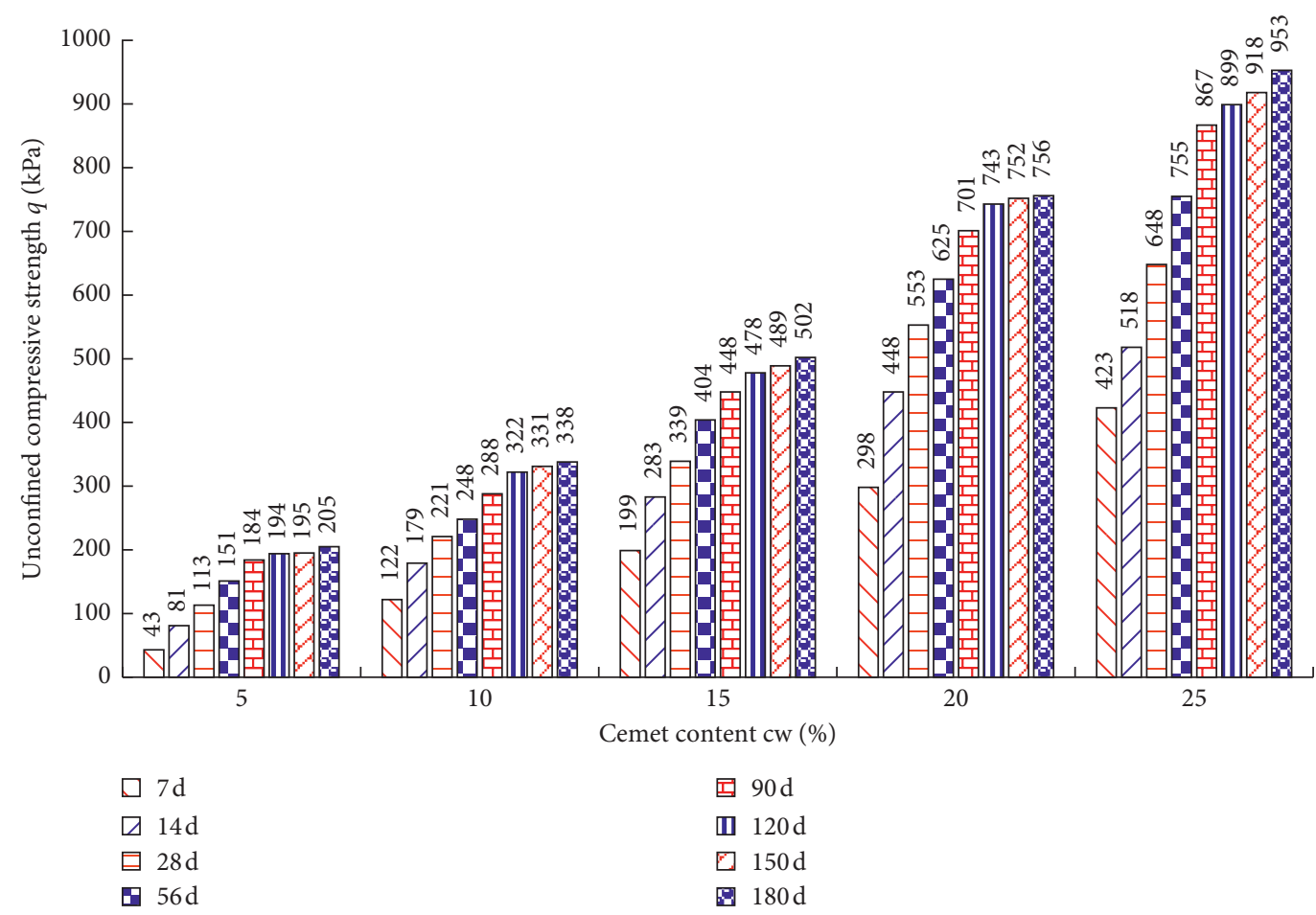

FIgURE 9: The UCS of the CMS with different cement contents and different curing ages.

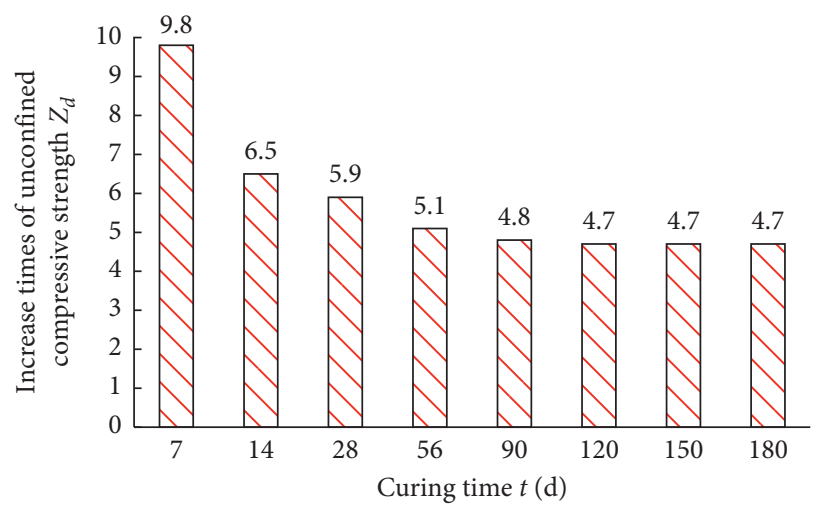

FIGURE 10: Multiple changes in the strength of the CMS with different cement contents during the curing process.

age on the UCS of the CMS, we obtained from Figures 7 and 8 that, with different cement contents, the UCS of the CMS had a similar change law with the increase in the curing age. The relationship between the UCS and curing age can be described by

$$
q=A \ln (t)+B
$$

where $q$ represents the UCS, $t$ represents the curing age, and $A$ and $B$ are functions of the cement content $c w$.

The prediction model of the UCS of the CMS with respect to the curing age can be obtained by fitting calculations:

$$
q= \begin{cases}50.008 \ln (t)-52.992 & c w=5 \%, \\ 66.735 \ln (t)-5.3395 & c w=10 \%, \\ 92.745 \ln (t)+28.09 & c w=15 \%, \\ 138.97 \ln (t)+63.96 & c w=20 \%, \\ 167.45 \ln (t)+91.182 & c w=25 \% .\end{cases}
$$

The calculated data of formula (4) were compared with the experimental data, as shown in Figure 11.

As can be seen from Figure 11, formula (4) can better predict the UCS of the CMS under different curing ages. In 


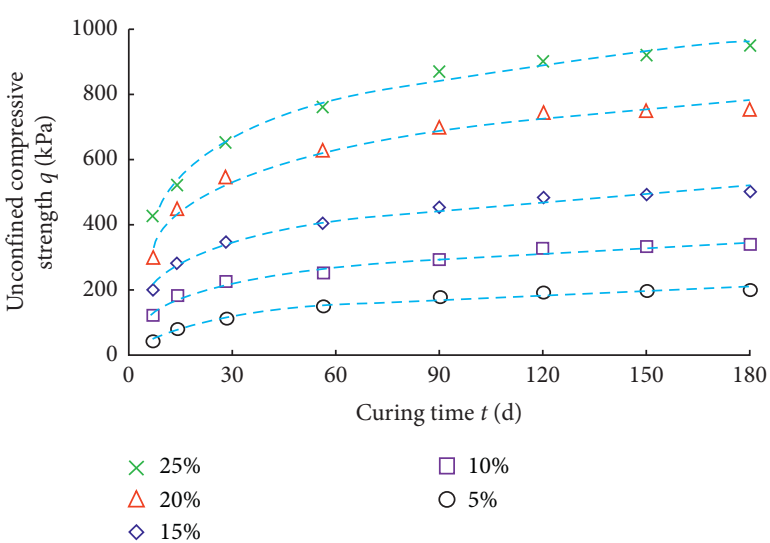

FIGURE 11: The UCS and curing age curve of the CMS with different cement contents.

order to consider the effect of the cement content on the UCS of the CMS, the function relation of A and B in formula (4), on the cement content $c w$, was fitted and calculated. The calculation functions of A and B can be obtained as shown in formulas (5) and (6), respectively.

$$
\begin{aligned}
& A=0.1249 c w^{2}+2.3949 c w+32.90, \\
& B=-0.1098 c w^{2}+10.446 c w-101.523 .
\end{aligned}
$$

The fitting curves of formulas (5) and (6) are shown in Figure 12. Both formulas (5) and (6) have better fitting accuracy.

Formulas (5) and (6) are substituted into formula (3), and the UCS prediction formula for CMS can be obtained:

$$
\begin{aligned}
q= & \left(0.1249 c w^{2}+2.3949 c w+32.906\right) \ln (t) \\
& +\left(-0.1098 c w^{2}+10.446 c w-101.52\right) .
\end{aligned}
$$

The measured UCS value of each group of CMS was compared with the predicted value calculated by formula (7), and the results are presented in Figure 13. We concluded that the correlation coefficient between the predicted value and the measured value was 0.991 , indicating that formula (7) can better predict the UCS of the CMS with different cement contents and different curing ages.

Formula (7) fit the measured strength of the CMS with $100 \%$ moisture content and had a good correlation. The UCS of the CMS increased linearly with the logarithm of the curing age. According to formula (7), the curve of the UCS of the CMS with different curing ages and different cement contents can be plotted, as shown in Figure 14, which can provide a reference for related engineering designs and practice.

\section{Microscopic Test and Mechanism Analysis}

In order to further explore the formation mechanism of the UCS of the CMS by the cement content and curing age, we used SEM, EDX, and XRD testing methods to test the

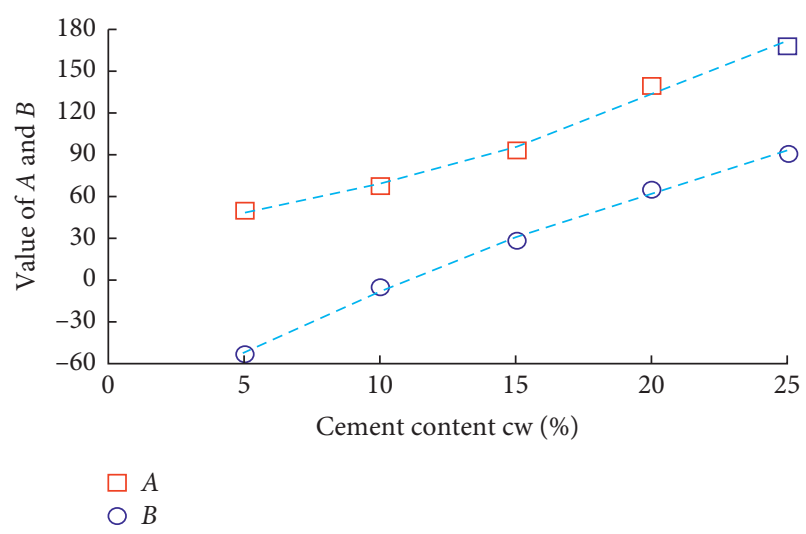

FIgURE 12: The relationship curves between A, B and the cement content cw.

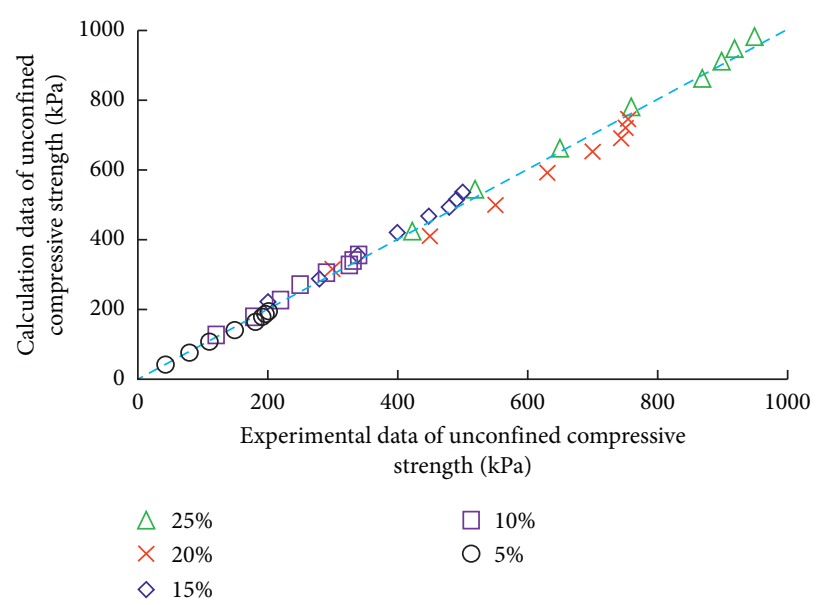

FIgURE 13: The correlation fitting curve between the prediction data and measured data.

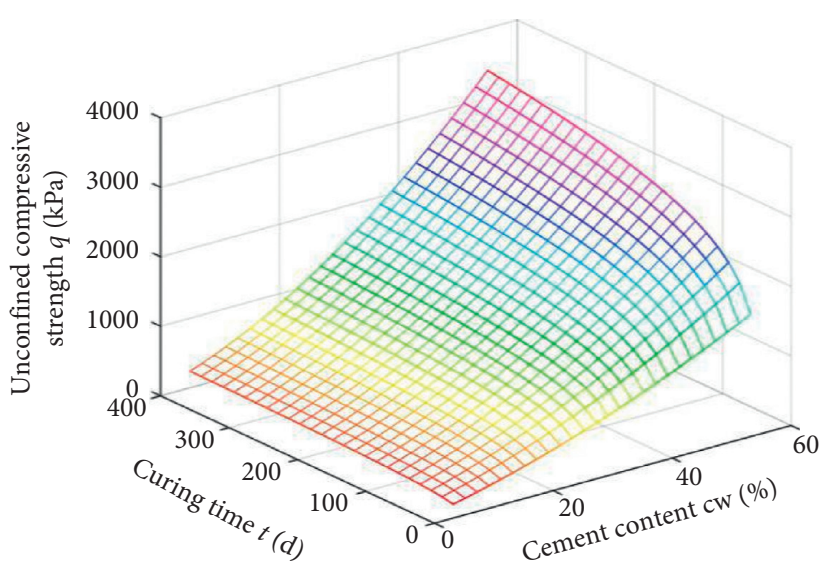

FIGURE 14: The prediction model of the UCS of the CMS.

microstructure, element changes, and compound change rules of CMS, so as to study the micromechanism of the time effect of CMS. The test scheme is shown in Table 4. 
TABlE 4: The CMS microtest scheme.

\begin{tabular}{lcc}
\hline Cement content/(\%) & Curing age/(d) & Test content \\
\hline 5 and 20 & 7,28 and 90 & SEM, EDX, and XRD \\
\hline
\end{tabular}

4.1. SEM Test. The SEM microtest is a popular microtest method commonly used in civil engineering and geotechnical engineering. SEM is used to enlarge the sample into the specified multiples, and the corresponding multiple microscopic images can be obtained directly. The uneven microstructure on the surface of the sample can be seen intuitively, and the particle distribution, pore distribution, and particle size inside the sample can be clearly observed. A JSM-6360LU tungsten filament high and low vacuum scanning electron microscope instrument produced by Japan Electronics Co., Ltd was used in this test. The SEM test was performed according to the test scheme in Table 4, and the SEM microscopic images of the CMS are shown in Figure 15.

When the curing age is $7 \mathrm{~d}$, the microstructure of CMS with a cement content of $5 \%$ is filled with more small particle units, few large particle units, a low degree of internal cementation, and a large number of pores, as shown in Figure 15(a). The microstructure of CMS with a cement content of $20 \%$ has larger pores, as shown in Figure 15(b). Compared with Figure 15(a), there are fewer small particle units and more large groups cemented together, forming a large group cemented loose structure at the microscopic scale. The reason is that, with the increasing cement content, after the hydration reaction, more gelling substances will be generated, which will further react to form crystals. In addition, these gelling substances will also wrap the slurry particles to cement them together to form a larger structure, thereby improving the strength of the slurry.

When the curing age was $28 \mathrm{~d}$, there was a small amount of gelling substance inside the CMS sample with a cement content of $5 \%$. However, there were interspaces inside the sample, and the cementation among the units was poor. The overall skeleton was more dispersed, as shown in Figure 15(c). In the microstructure of the CMS with a cement content of $20 \%$, the large particle units became significantly larger, and a small amount of the small particle units is attached to the large particles, as shown in Figure 15(d). Compared with Figure 15(b), the microstructure of the CMS at the $28 \mathrm{~d}$ curing age was more compact, which was reflected in the increase of strength, microscopically.

When the curing age was $90 \mathrm{~d}$, compared with the curing age of $7 \mathrm{~d}$ and $28 \mathrm{~d}$, the microstructure of the CMS sample with a cement content of $5 \%$ had a larger number of large particle units, with only a few small particle units. The degree of cementation between the large particle units was improved, and the pores between the samples decreased. The cementation between units was poor, and the overall skeleton was relatively dispersed, as shown in Figure 15(e). This is because the cement content was too small, resulting in less gelling substances generated by cement hydration, which could not fill the internal pores of the CMS. In the microstructure of the CMS with a cement content of $20 \%$, the overall cementation degree was further deepened, and the structure was more compact, presenting a complete skeleton as shown in Figure 15(f).

We concluded from the above analysis that, with the increase in curing age and cement content, the gelling substances in the microstructure of CMS gradually increased, filling the pores among the soil particles, thereby improving the microstructure compactness of the CMS. Macroscopically, the UCS of the CMS gradually increased with the increase in the curing age and cement content.

4.2. EDX Test. By means of high-energy X-ray, the X-ray energy spectrometer recoordinated the atoms in the sample atoms, and the electrons in the outer layer supplemented the vacancy of the electrons in the inner layer, thus releasing the characteristic X-rays, whose wavelength has a certain relationship with the atomic number. Qualitative analysis can be performed according to the wavelength of the spectral line, and the content of the element can also be obtained. The $\mathrm{X}$-ray energy spectrometer used in this test was the British Oxford X-act energy spectrometer produced by the Beijing OBR Scientific Instrument Co., Ltd. The EDX test was performed according to the test scheme in Table 4, and the energy spectrum of the CMS was obtained as shown in Figure 16.

It can be seen from Figure 16 that the main elements in the CMS are $\mathrm{Si}, \mathrm{O}, \mathrm{Al}$, and $\mathrm{Ca}$. This is because the main minerals, dicalcium silicate and tricalcium silicate, in cement undergo a hydration reaction with water, resulting in the production of gelling substances to improve the strength of the slurries. The chemical components in gelling substances are mainly $\mathrm{Si}, \mathrm{O}, \mathrm{Al}$, and $\mathrm{Ca}$ elements.

4.3. XRD Test. The X-ray diffractometer is an analytical instrument for researching and identifying the composition and atomic structure of crystalline substances and materials. The wavelength of X-rays is close to the distance between the atomic surfaces inside the crystal. The crystal can be used as a spatial diffraction grating of X-rays. That is, when an X-ray beam is irradiated on an object, it is scattered by the atoms in the object, and each atom generates a scattered wave. These waves interfere with each other, resulting in diffraction. The superposition of the diffraction waves makes the intensity of the rays strengthen in some directions and weaken in other directions. By analyzing the diffraction results, the crystal structure can be obtained, and its composition can be analyzed. The XRD test was performed according to the test scheme in Table 4, and the X-ray diffraction analysis chart of the CMS is shown in Figure 17.

It can be seen from Figure 17 that the compounds in the CMS are mainly $\mathrm{SiO}_{2}, \mathrm{Al}_{2} \mathrm{O}_{3}$, and $\mathrm{CaCO}_{3}$, which are in good agreement with the EDX test results. According to the XRD test results, the mass ratios of $\mathrm{SiO}_{2}, \mathrm{CaCO}_{3}$, and $\mathrm{Al}_{2} \mathrm{O}_{3}$ at the curing ages of $7 \mathrm{~d}, 28 \mathrm{~d}$, and $90 \mathrm{~d}$ with a cement content of $5 \%$ and $20 \%$ can be obtained through statistics, as shown in Figure 18. 


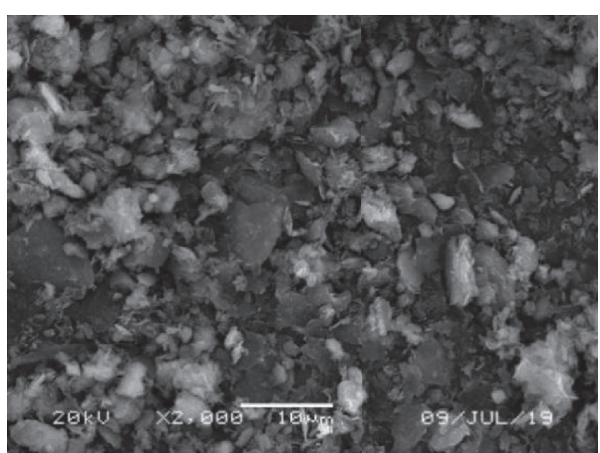

(a)

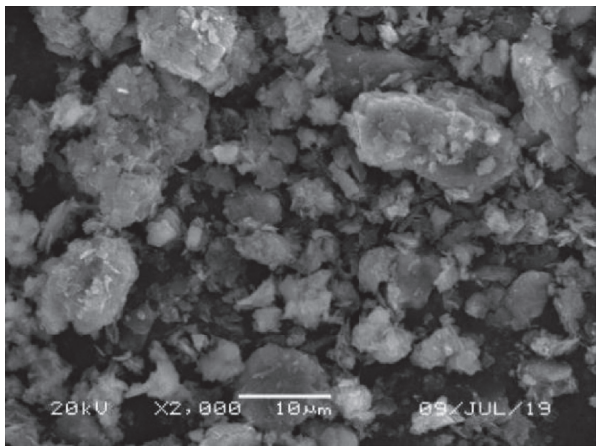

(c)

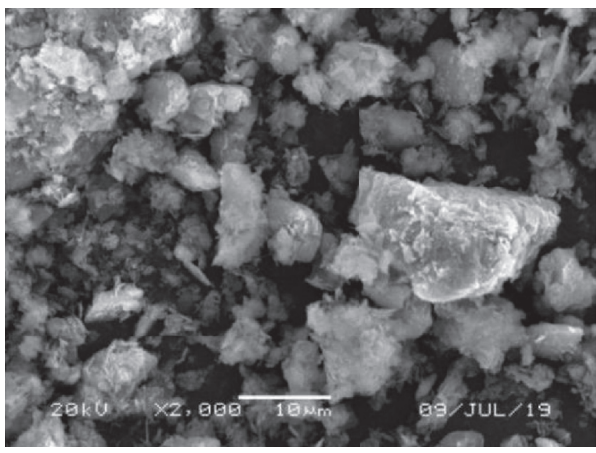

(e)

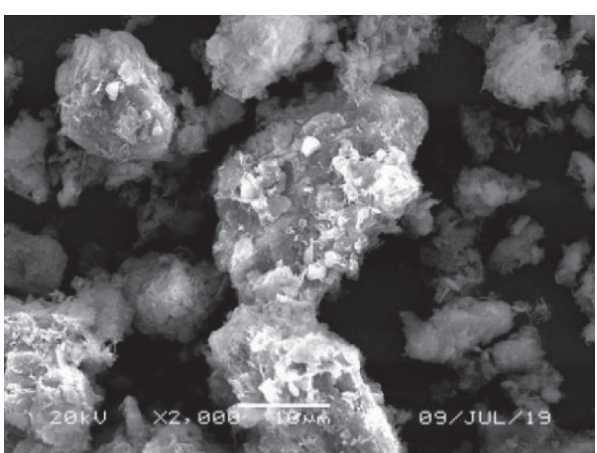

(b)

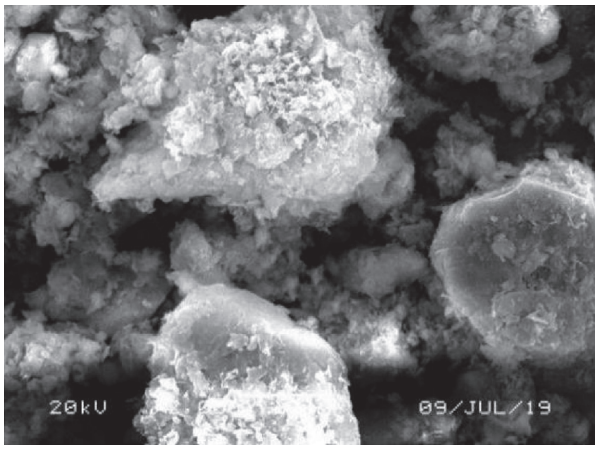

(d)

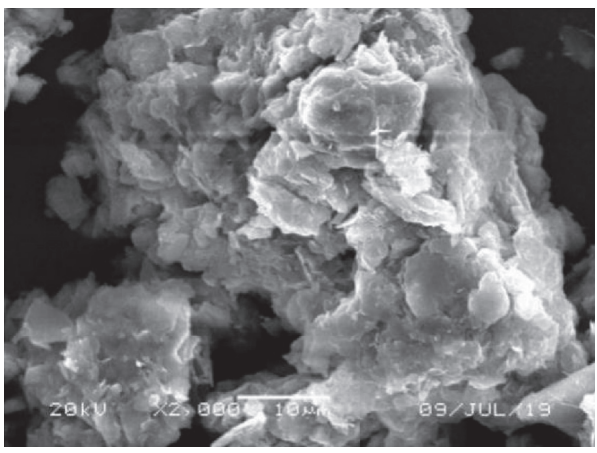

(f)

Figure 15: SEM images of CMS with different cement contents and curing ages. (a) Cement content 5\% and curing age 7 (d). (b) Cement content $20 \%$ and curing age 7 (d). (c) Cement content $5 \%$ and curing age 28 (d). (d) Cement content $20 \%$ and curing age 28 (d). (e) Cement content $5 \%$ and curing age 90 (d). (f) Cement content $20 \%$ and curing age $90 \mathrm{~d}$.

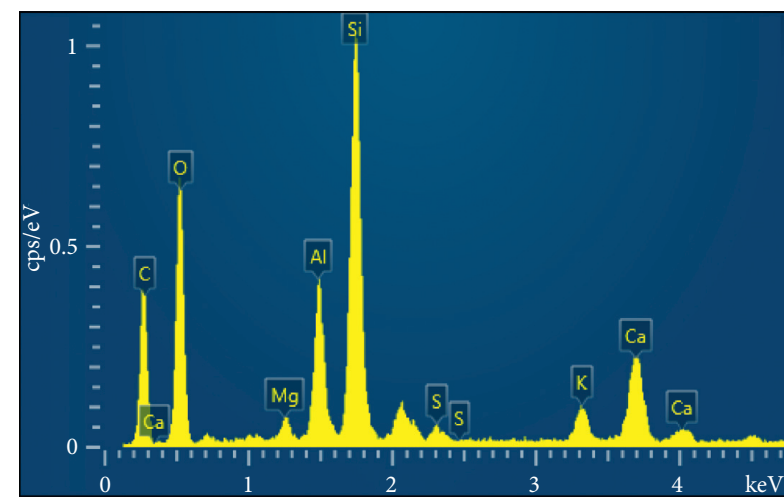

General spectrum

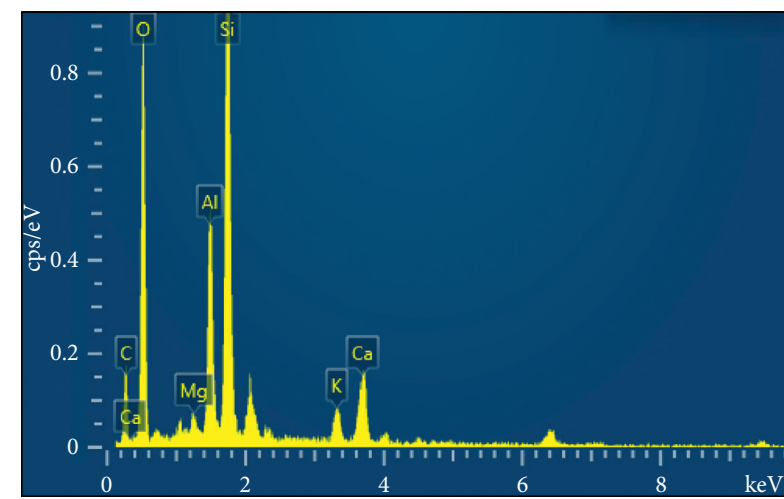

General spectrum

(a)

(b)

Figure 16: Continued. 


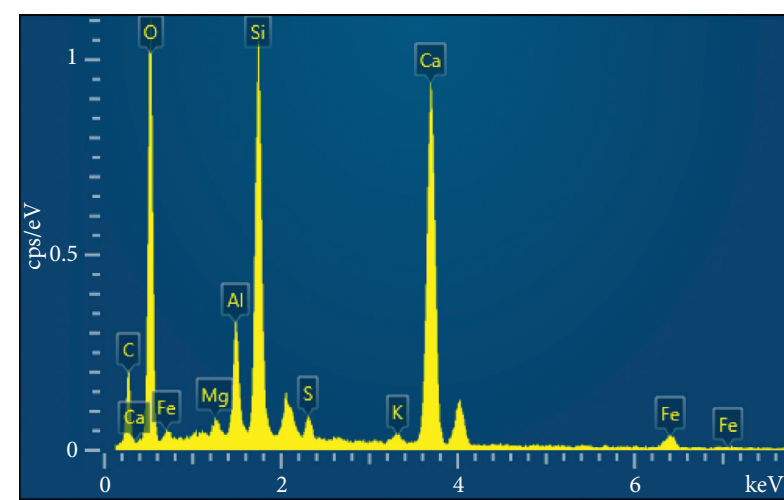

General spectrum

(c)

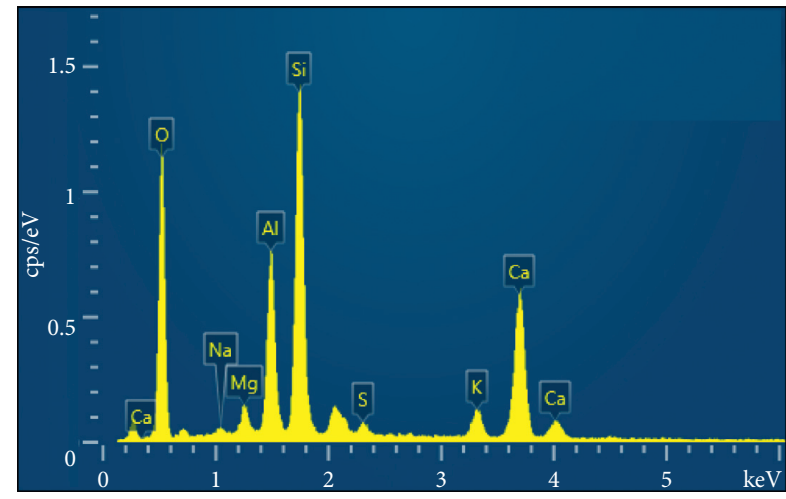

General spectrum

(e)

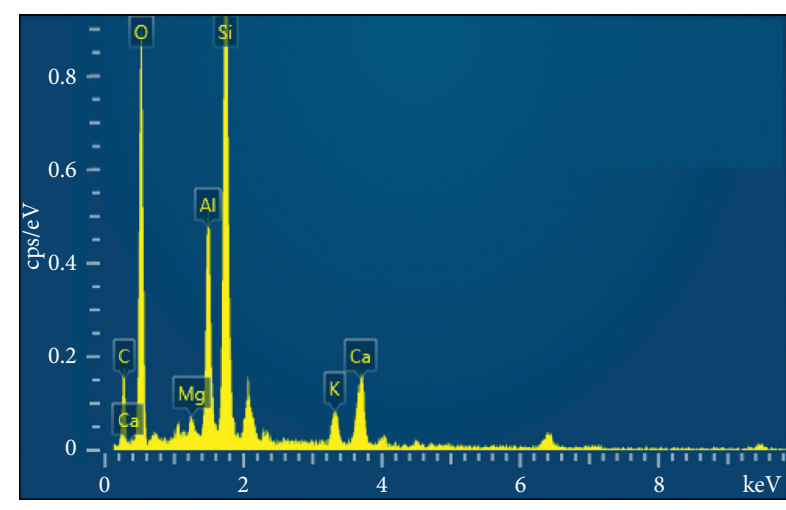

General spectrum

(d)

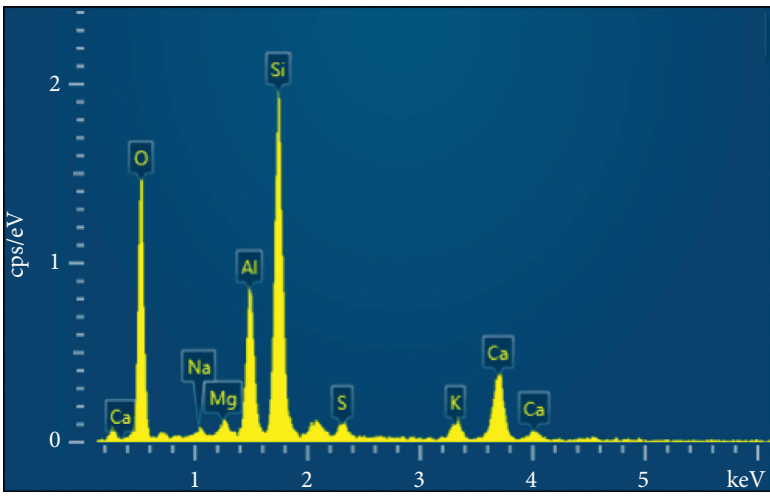

General spectrum

FiguRE 16: EDX test results under different cement content and curing age. (a) Cement content 5\% and curing age 7 (d). (b) Cement content $5 \%$ and curing age 28 (d). (c) Cement content 5\% and curing age 90 (d). (d) Cement content $20 \%$ and curing age 7 (d). (e) Cement content $20 \%$ and curing age 28 (d). (f) Cement content $20 \%$ and curing age $90 \mathrm{~d}$.

It can be seen from Figure 18 that the mass ratios of $\mathrm{SiO}_{2}$, $\mathrm{Al}_{2} \mathrm{O}_{3}$, and $\mathrm{CaCO}_{3}$ increased with the increasing cement content and curing age.

According to reference [31], the direction index of $\mathrm{SiO}_{2}$ can be calculated. The relative UCS and relative direction index are calculated based on the strength and direction coefficient of the CMS with a cement content of $20 \%$ and at a $28 \mathrm{~d}$ curing age. The calculated results are shown in Figure 19.

As can be seen from Figure 19, there is a negative linear correlation between the relative UCS and relative direction coefficient. That is, as the UCS increases, the direction coefficient gradually decreases.

4.4. Micromechanical Analysis. We concluded through the EDX and XRD tests that, under the same curing age, the mass ratios of $\mathrm{Si}, \mathrm{Al}$, and $\mathrm{Ca}$ increased with the increase of cement content, due to the chemical reaction between the cement and soil particles and the water inside the slurry. The higher the cement content was, the more the dicalcium silicate, tricalcium silicate, and alumina were produced by the reaction. With the same cement content, the mass ratios of $\mathrm{Si}, \mathrm{Al}$, and $\mathrm{Ca}$ elements increased with the increase in the curing age. This is because the strength improvement effect of the dicalcium silicate began to play its role after curing for 28 days. As the curing age increased, the hydration reaction of the cement became more and more sufficient, and more hydration products are generated.

As can be seen in Figure 17, the composition and types of the compounds did not change along with the increase of the cement content and curing age. This is because the main components of cement are dicalcium silicate $\left(\mathrm{C}_{2} \mathrm{~S}\right)$, tricalcium silicate $\left(\mathrm{C}_{3} \mathrm{~S}\right)$, tricalcium aluminate $\left(\mathrm{C}_{3} \mathrm{~A}\right)$, tetracalcium iron aluminate $\left(\mathrm{C}_{4} \mathrm{AF}\right)$, and the hydration reaction equations are shown in equations (8)-(11), respectively: 


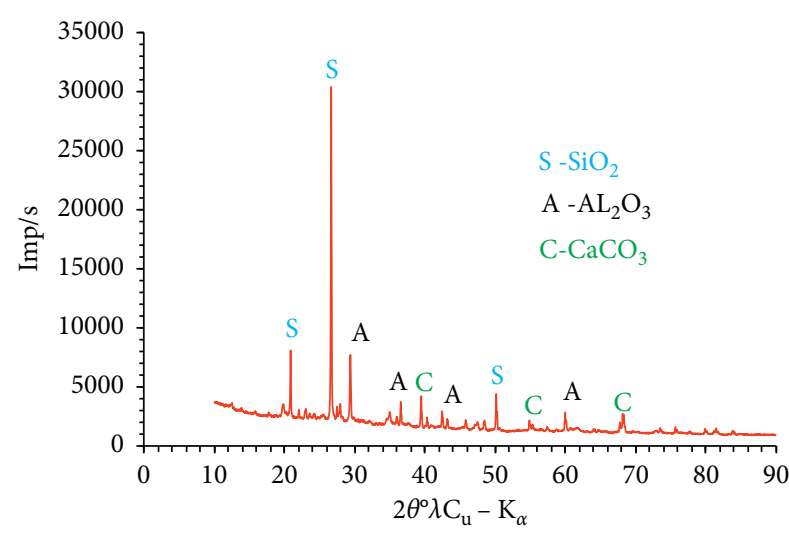

(a)

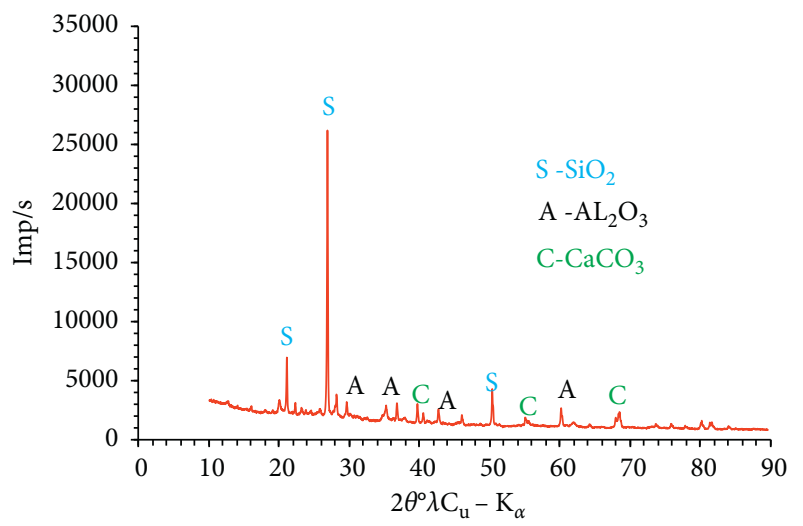

(c)

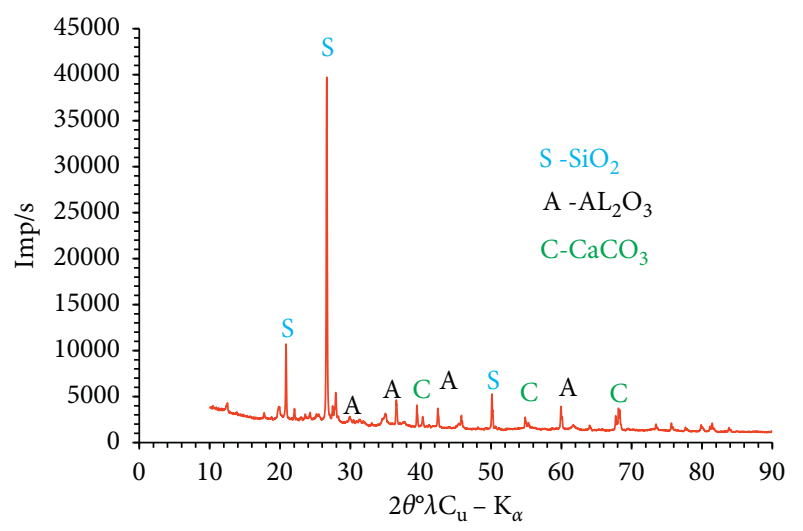

(e)

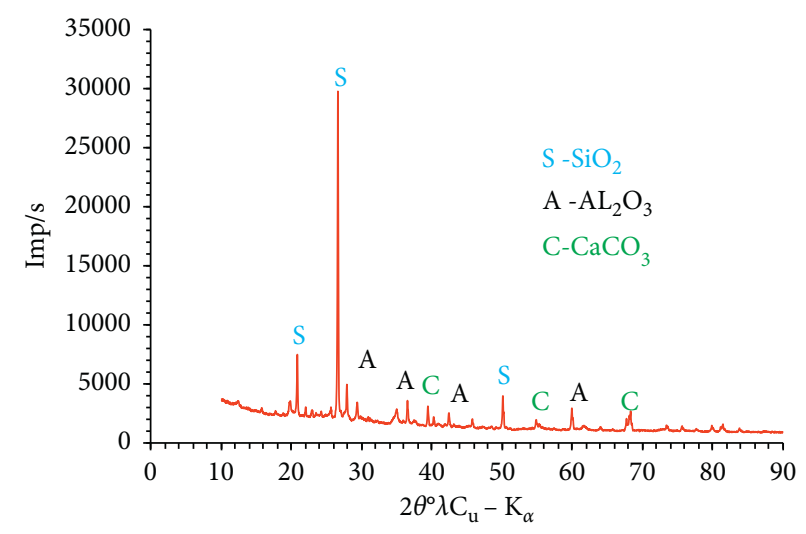

(b)

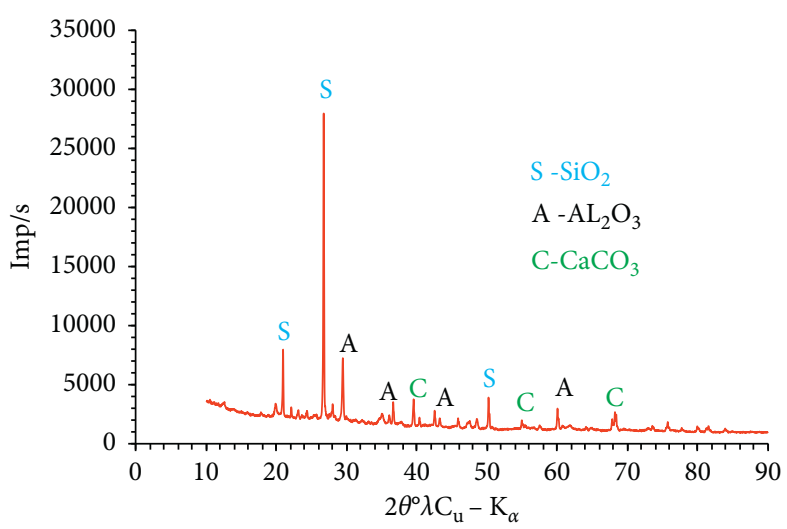

(d)

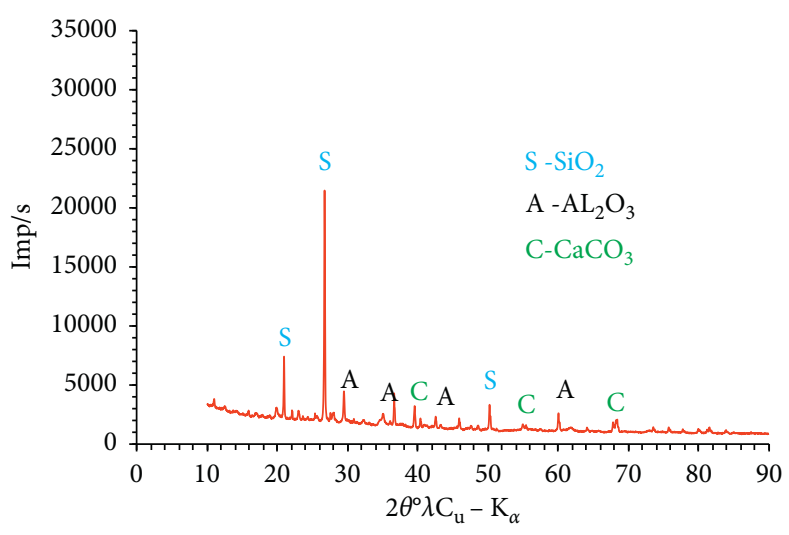

(f)

Figure 17: The XRD images of different cement contents and curing ages. (a) Cement content 5\% and curing age $7 \mathrm{~d}$. (b) Cement content $20 \%$ and curing age $7 \mathrm{~d}$. (c) Cement content $5 \%$ and curing age $28 \mathrm{~d}$. (d) Cement content $20 \%$ and curing age $28 \mathrm{~d}$. (e) Cement content $5 \%$ and curing age $90 \mathrm{~d}$. (f) Cement content $20 \%$ and curing age $90 \mathrm{~d}$.

$$
\begin{aligned}
x\left(2 \mathrm{CaO} \cdot \mathrm{SiO}_{2}\right)+y \mathrm{H}_{2} \mathrm{O} & =z \mathrm{CaO} \cdot x \mathrm{SiO}_{2}(y-2 x+z) \mathrm{H}_{2} \mathrm{O}+(2 x-z) \mathrm{Ca}(\mathrm{OH})_{2} \\
m\left(3 \mathrm{CaO} \cdot \mathrm{SiO}_{2}\right)+n \mathrm{H}_{2} \mathrm{O} & =k \mathrm{CaO} \cdot m \mathrm{SiO}_{2}(n-3 m+k) \mathrm{H}_{2} \mathrm{O}+(3 m-k) \mathrm{Ca}(\mathrm{OH})_{2}, \\
3 \mathrm{CaO} \cdot \mathrm{Al}_{2} \mathrm{O}_{3}+6 \mathrm{H}_{2} \mathrm{O} & =3 \mathrm{CaO} \cdot \mathrm{Al}_{2} \mathrm{O}_{3} 6 \mathrm{H}_{2} \mathrm{O} \\
4 \mathrm{CaO} \cdot \mathrm{Al}_{2} \mathrm{O}_{3} \cdot \mathrm{Fe}_{2} \mathrm{O}_{3}+7 \mathrm{H}_{2} \mathrm{O} & =3 \mathrm{CaO} \cdot \mathrm{Al}_{2} \mathrm{O}_{3} \cdot 6 \mathrm{H}_{2} \mathrm{O}+\mathrm{CaO} \cdot \mathrm{Fe}_{2} \mathrm{O}_{3} \cdot \mathrm{H}_{2} \mathrm{O} .
\end{aligned}
$$




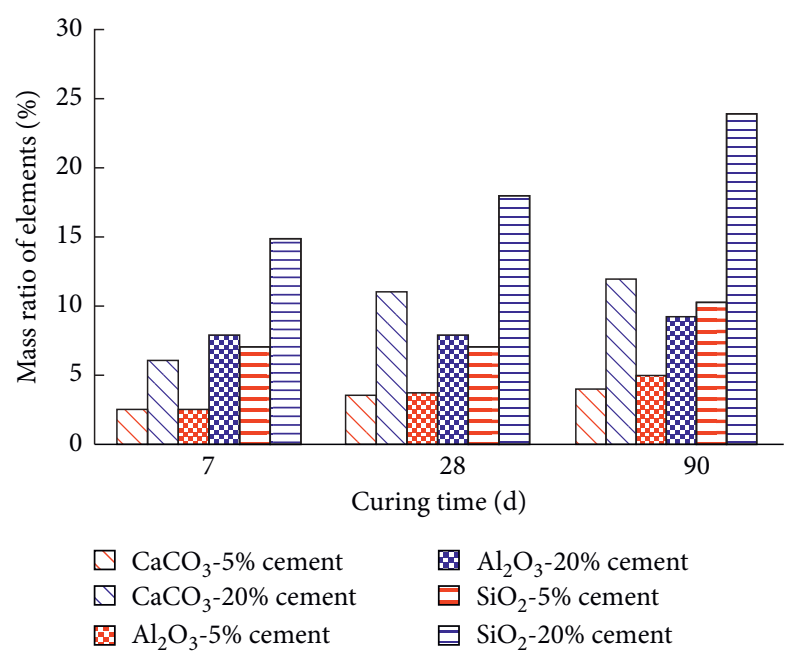

FIGURE 18: The relationship between mass ratios of various elements with different cement contents.

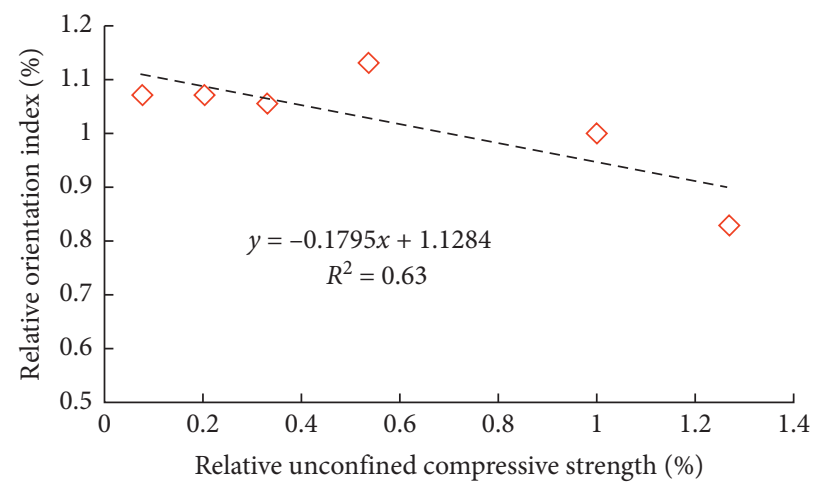

FIGURE 19: The relationship curve between the relative UCS and relative direction coefficients.

The hydration reaction of $\mathrm{C} 2 \mathrm{~S}$ and $\mathrm{C} 3 \mathrm{~S}$ is the main reason for the formation of CMS strength. The action times of the two mineral components are different. C3S generally exerts its improvement effect within 28 days, while C2S begins to exert its effect after 28 days. Therefore, with the increase in curing age, the hydration reaction products increased, and the corresponding $\mathrm{Si}, \mathrm{O}, \mathrm{Al}, \mathrm{Ca}$, and the other elements increased. Therefore, it can be explained from the perspective of the element composition that the UCS of the CMS increased with the increase in curing age.

According to Figure 17, under the same curing age, the $\mathrm{SiO}_{2}, \mathrm{CaCO}_{3}$, and $\mathrm{Al}_{2} \mathrm{O}_{3}$ contents of CMS increased with the increase of cement content. As a result, the hydration reaction products in CMS increased to improve its UCS.

\section{Conclusions and Discussions}

5.1. Conclusions. By studying the time effect and micromechanisms of the UCS of the CMS, the following conclusions can be obtained:

(1) With the increase of the cement content and curing age, the UCS of the CMS improved significantly. From the curing age of $7 \mathrm{~d}$ to $180 \mathrm{~d}$, the UCS of the
CMS in each curing age increased with the increase of cement content, and the growth rate of the UCS of the CMS with a cement content from $20 \%$ to $25 \%$ significantly decreased. Thus, we concluded that the $20 \%$ cement content was the optimal content.

(2) With the cement content from $5 \%$ to $25 \%$, the UCS of the CMS at each cement content increased first and then tended to be constant with the increase in the curing age. The UCS at the curing age of $180 \mathrm{~d}$ was about 2.5 times higher than that at $7 \mathrm{~d}$.

(3) Based on the mathematical characteristics of the strength-age curve and the strength-cement content curve, a time effect model was established, which could better characterize the relationship between the UCS of the CMS and the curing age and the cement content. This can effectively predict and guide the use of CMS in engineering practice.

(4) The strength formation mechanism of CMS mainly includes the following two aspects: on one hand, the hydration reaction of $\mathrm{C} 2 \mathrm{~S}$ and $\mathrm{C} 3 \mathrm{~S}$ in cement generated gelling substances, which fill the pores among the particles, thereby improving the strength of CMS. On the other hand, with the increase of the cement 
content and curing age, more and more gelling substances were formed, which results in the small particles clumping together to form a larger cement soil mass, thus increasing the strength of the CMS.

5.2. Discussions. The strength change law of CMS under different curing ages was obtained by UCS tests and microscopic test. It should be noted that:

(1) This study only discussed the UCS time effect of CMS with $100 \%$ moisture content. For other representative moisture contents, such as optimal moisture content, plastic limit and liquid limit, the UCS time effect model of CMS needs to be further studied.

(2) Environmental factors have a certain influence on the UCS of CMS, so it is necessary to study the modification of time effect model of CMS by dry wet cycles and freeze-thaw cycles.

(3) The role of other materials such as nanomaterials [32, 33], polymer materials [34-36], and fibers [37-40] can improve the mechanical properties of building materials, and it is necessary to study the application of these materials in CMS modification.

\section{Data Availability}

The data used to support the findings of this study are available from the corresponding author upon request.

\section{Conflicts of Interest}

The authors declare that they have no conflicts of interest.

\section{Authors' Contributions}

W. W. and J. Y. conceptualized the study L. Z. and T. M. performed investigation; P. J. wrote the original draft; Y. C. and $\mathrm{N}$. L reviewed and edited the article. All authors have read and agreed to the published version of the manuscript.

\section{Acknowledgments}

This research was funded by the National Natural Science Foundation of China (Grant number 41772311), the Zhejiang Provincial Natural Science Foundation of China (Grant number Q20E080042), the Open Research Fund of Key Laboratory of Ministry of Education for Geomechanics and Embankment Engineering of Hohai University (Grant number 2019020), and the Open Research Fund of State Key Laboratory of Geomechanics and Geotechnical Engineering, Institute of Rock and Soil Mechanics, Chinese Academy of Science (Grant number Z017013).

\section{References}

[1] C. Zhang, J. Fu, J. Yang, X. Ou, X. Ye, and Y. Zhang, "Formulation and performance of grouting materials for underwater shield tunnel construction in karst ground," Construction and Building Materials, vol. 187, pp. 327-338, 2018.
[2] Y. Chen, S. Gao, L. Chen, G. Chen, and J. Chen, "Laboratory and field test study on the improvement of marine clay slurry by in-situ solidification," Marine Georesources \& Geotechnology, vol. 37, no. 6, pp. 695-703, 2019.

[3] Y. Cheng, S. Wang, J. Li, X. Huang, C. Li, and J. Wu, "Engineering and mineralogical properties of stabilized expansive soil compositing lime and natural pozzolans," Construction and Building Materials, vol. 187, pp. 1031-1038, 2018.

[4] P. Jiang, T. Mao, N. Li, L. Jia, F. Zhang, and W. Wang, "Characterization of short-term strength properties of fiber/ cement-modified slurry," Advances in Civil Engineering, vol. 20199 pages, 2019.

[5] K. Yao, Q. S. Chen, J. H. Ho, H. W. Xiao, and F. H. Lee, "Strain-dependent shear stiffness of cement-treated marine clay," Journal of Materials in Civil Engineering, vol. 30, Article ID 04018255, 2018.

[6] K. Yao, N. Li, D.-H. Chen, and W. Wang, "Generalized hyperbolic formula capturing curing period effect on strength and stiffness of cemented clay," Construction and Building Materials, vol. 199, pp. 63-71, 2019.

[7] W. Wang, C. Zhang, N. Li, F. Tao, and K. Yao, "Characterisation of nano magnesia-cement-reinforced seashore soft soil by direct-shear test," Marine Georesources \& Geotechnology, vol. 37, no. 8, pp. 989-998, 2019.

[8] K. Yao, D. An, W. Wang, N. Li, C. Zhang, and A. Zhou, "Effect of nano-mgo on mechanical performance of cement stabilized silty clay," Marine Georesources \& Geotechnology, vol. 38, no. 2, pp. 250-255, 2020.

[9] N. Li, S. W. Lv, W. Wang, J. Guo, P. Jiang, and Y. Liu, "Experimental investigations on the mechanical behavior of iron tailings powder with compound admixture of cement and nano-clay," Construction and Building Materials, vol. 254, Article ID 119259, 2020.

[10] W. Wang, Y. Li, K. Yao, N. Li, A. Z. Zhou, and C. Zhang, "Strength properties of nano-MgO and cement stabilized coastal silty clay subjected to sulfuric acid attack," Marine Georesources \& Geotechnology, vol. 3, pp. 1-10, 2019.

[11] S.-Y. Pu, Z.-D. Zhu, W.-L. Song, H.-R. Wang, and R.-J. Wei, "Deformation properties of silt solidified with a new SEU-2 binder," Construction and Building Materials, vol. 220, pp. 267-277, 2019.

[12] N. Yoobanpot, P. Jamsawang, and S. Horpibulsuk, "Strength behavior and microstructural characteristics of soft clay stabilized with cement kiln dust and fly ash residue," Applied Clay Science, vol. 141, pp. 146-156, 2016.

[13] G. Dai, Y. Sheng, Y. Pan, G. Shi, and S. Li, "Application of a bentonite slurry modified by polyvinyl alcohol in the cutoff of a landfill," Advances in Civil Engineering, vol. 2020, pp. 1-9, 2020.

[14] Y. X. Wu, S. L. Shen, Z. Y. Yin, and Y. S. Xu, "Characteristics of groundwater seepage with cut-off wall in gravel aquifer. II: numerical analysis," Canadian Geotechnical Journal, vol. 52, Article ID 150223161106004, 2015.

[15] Y. Pan and Y. Fu, "Effect of random geometric imperfections on the water-tightness of diaphragm wall," Journal of $\mathrm{Hy}$ drology, vol. 580, Article ID 124252, 2019.

[16] Y. Pan, Y. Liu, A. Tyagi, F.-H. Lee, and D.-Q. Li, "Modelindependent strength-reduction factor for effect of spatial variability on tunnel with improved soil surrounds," Géotechnique, vol. 3, pp. 1-17, 2020.

[17] P. Croce and G. Modoni, "Design of jet-grouting cut-offs," Ground Improvement, vol. 10, no. 1, pp. 1-9, 2007.

[18] J. J. Zheng, Y. Liu, Y. T. Pan, and J. Hu, "Statistical evaluation of the load-settlement response of a multicolumn composite 
foundation," International Journal of Geomechanics, vol. 18, no. 4, Article ID 04018015, 2018.

[19] A. Tyagi, Y. Liu, Y. T. Pan, K. Bte, and M. Ridhwan, "Stability of tunnels in cement-admixed soft soils with spatial variability," Journal of Geotechnical \& Geoenvironmental Engineering, vol. 144, no. 12, pp. 1-7, 2018.

[20] Y. Liu, F.-H. Lee, S.-T. Quek, E. J. Chen, and J.-T. Yi, "Effect of spatial variation of strength and modulus on the lateral compression response of cement-admixed clay slab," Géotechnique, vol. 65, no. 10, pp. 851-865, 2015.

[21] Y. Liu, L. Q. He, Y. J. Jiang, M. M. Sun, E. J. Chen, and F.-H. Lee, "Effect of in situ water content variation on the spatial variation of strength of deep cement-mixed clay," Géotechnique, vol. 69, no. 5, pp. 391-405, 2019.

[22] S. Horpibulsuk, N. Miura, and T. S. Nagaraj, "Assessment of strength development in cement-admixed high water content clays with Abrams' law as a basis," Géotechnique, vol. 53, no. 4 , pp. 439-444, 2003.

[23] F.-H. Lee, Y. Lee, S.-H. Chew, and K.-Y. Yong, "Strength and modulus of marine clay-cement mixes," Journal of Geotechnical and Geoenvironmental Engineering, vol. 131, no. 2, pp. 178-186, 2005.

[24] H. Xiao, F. H. Lee, and K. G. Chin, "Yielding of cementtreated marine clay," Soils and Foundations, vol. 54, no. 3, pp. 488-501, 2014.

[25] Y. Liu, Y. J. Jiang, H. Xiao, and F. H. Lee, "Determination of representative strength of deep cement-mixed clay from core strength data," Géotechnique, vol. 67, no. 4, pp. 1-15, 2017.

[26] S. E. Mousavi, "Stabilization of compacted clay with cement and/or lime containing peat ash," Road Materials and Pavement, vol. 18, pp. 1-18, 2017.

[27] H. Mola-Abasi, B. Kordtabar, and A. Kordnaeij, "Effect of natural zeolite and cement additive on the strength of sand," Geotechnical and Geological Engineering, vol. 34, no. 5, pp. 1-13, 2016.

[28] N. Ghasabkolaei, A. Janalizadeh, M. Jahanshahi, N. Roshan, and S. E. Ghasemi, "Physical and geotechnical properties of cement-treated clayey soil using silica nanoparticles: an experimental study," The European Physical Journal Plus, vol. 131, no. 5, pp. 1-11, 2016.

[29] A. A. Al-Homidy, M. H. Dahim, and A. K. Abd El Aal, "Improvement of geotechnical properties of sabkha soil utilizing cement kiln dust," Journal of Rock Mechanics and Geotechnical Engineering, vol. 9, no. 4, pp. 749-760, 2017.

[30] China National Standards JTG/3430-2020, Test Method of Soils for Highway Engineering, People's Communications Press, Beijing, China, 2020.

[31] J. Liu, J. Fu, T. Ni, and Y. Yang, "Fracture toughness improvement of multi-wall carbon nanotubes/graphene sheets reinforced cement paste," Construction and Building Materials, vol. 200, pp. 530-538, 2019.

[32] W. Wang, J. Li, and J. Hu, "Unconfined mechanical properties of nanoclay cement compound modified calcareous sand of the South China Sea," Advances in Civil Engineering, vol. 2020, Article ID 6623710, 16 pages, 2020.

[33] W. Wang, Y. Li, K. Yao, N. Li, A. Zhou, and C. Zhang, "Strength properties of nano-MgO and cement stabilized coastal silty clay subjected to sulfuric acid attack," Marine Georesources \& Geotechnology, vol. 38, no. 10, pp. 1177-1186, 2020.

[34] M. Guo and Y. Tan, "Interaction between asphalt and mineral fillers and its correlation to mastics' viscoelasticity," International Journal of Pavement Engineering, vol. 22, no. 1, p. 1, 2019.
[35] M. Guo, H. Q. Liu, Y. B. Jiao et al., "Effect of WMA-RAP Technology on pavement performance of asphalt mixture: a state-of-the-art review," Journal of Cleaner Production, vol. 266, Article ID 121704, 2020.

[36] M. Guo, M. C. Liang, W. Zhao, Y. X. Duan, and H. Q. Liu, “A review of phase change materials in asphalt binder and asphalt mixture," Construction and Building Materials, vol. 258, Article ID 119565, 2020.

[37] N. Li, Y. Zhu, F. Zhang, S. M. Lim, W. Wu, and W. Wang, "Unconfined compressive properties of fiber-stabilized coastal cement clay subjected to freeze-thaw cycles," Journal of Marine Science and Engineering, vol. 9, no. 2, p. 143, 2021.

[38] Q. Guo, Z. Chen, P. Liu et al., "Influence of basalt fiber on mode I and II fracture properties of asphalt mixture at medium and low temperatures," Theoretical and Applied Fracture Mechanics, vol. 112, Article ID 102884, 2021.

[39] P. Jiang, S. L. Lv, Y. Wang, N. Li, and W. Wang, "Investigation on direct shear and energy dissipation characteristics of iron tailings powder reinforced by polypropylene fiber," Applied Sciences, vol. 9, pp. 50-98, 2019.

[40] Q. Guo, L. Li, Y. Cheng, Y. Jiao, and C. Xu, "Laboratory evaluation on performance of diatomite and glass fiber compound modified asphalt mixture," Materials \& Design (1980-2015), vol. 66, pp. 51-59, 2015. 